\title{
(C) OPEN ACCESS \\ Cultural crossings of care: An appeal to the medical humanities
}

\author{
Julia Kristeva, ${ }^{1}$ Marie Rose Moro, ${ }^{2}$ John Ødemark, ${ }^{3}$ Eivind Engebretsen ${ }^{4}$
}

${ }^{1}$ Centre d'Études et de Recherches Interdisciplinaires en Lettres Arts Cinéma, Université Paris VII—Denis Diderot, Paris, France

${ }^{2}$ Maison des AdolescentsHopital Cochin, Université Paris Descartes, Paris, France ${ }^{3}$ Department of Cultural Studies and Oriental Languages, Faculty of Humanities, University of Oslo, Oslo, Norway ${ }^{4}$ Institute of Health and Society, Faculty of Medicine, University of Oslo, Oslo, Norway

\section{Correspondence to} Professor Eivind Engebretsen, Faculty of Medicine, University of Oslo, Box 1078 Blindern, Oslo 0316, Norway; eivind.engebretsen@medisin. uio no

Accepted 10 August 2017 Published Online First 21 September 2017
Check for updates

To cite: Kristeva J, Moro MR, Ødemark J, et al. Med Humanit 2018:44:55-58.

\section{ABSTRACT}

Modern medicine is confronted with cultural crossings in various forms. In facing these challenges, it is not enough to simply increase our insight into the cultural dimensions of health and well-being. We must, more radically, question the conventional distinction between the 'objectivity of science' and the 'subjectivity of culture'. This obligation creates an urgent call for the medical humanities but also for a fundamental rethinking of their grounding assumptions.

Julia Kristeva (JK) has problematised the biomedical concept of health through her reading of the anthropogony of Cura (Care), who according to the Roman myth created man out of a piece of clay. JK uses this fable as an allegory for the cultural distinction between health construed as a 'definitive state', which belongs to biological life (bios), and healing as a durative 'process with twists and turns in time' that characterises human living (zoe). A consequence of this demarcation is that biomedicine is in constant need of 'repairing' and bridging the gap between bios and zoe, nature and culture. Even in radical versions, the medical humanities are mostly reduced to such an instrument of repairment, seeing them as what we refer to as a soft, 'subjective' and cultural supplement to a stable body of 'objective', biomedical and scientific knowledge. In this article, we present a prolegomenon to a more radical programme for the medical humanities, which calls the conventional distinctions between the humanities and the natural sciences into question, acknowledges the pathological and healing powers of culture, and sees the body as a complex biocultural fact. A key element in such a project is the rethinking of the concept of 'evidence' in healthcare.

\section{INTRODUCTION}

Modern medicine is confronted with cultural crossings in various forms: The migration wave imposes a new awareness of the cultural dimensions of both physical and psychological therapy. ${ }^{1}$ Religious and ideological radicalisation raises new questions about how to draw the line between pathology and conviction, and how to deal with cultural and religious discontent, also in clinical settings. ${ }^{2}$ The Lancet Commission on Culture and Health from 2014 provided important insights into the cultural dimensions of health and well-being. Even more radically, it pointed out that 'the distinction between the objectivity of science and the subjectivity of culture' is 'itself a social fact'. ${ }^{1}$

In line with the Lancet Commission, we maintain that there is a need to fundamentally question the cultural distinction between the objectivity of science and the subjectivity of culture, the generality of the natural sciences and the singularity of the humanities. We believe, moreover, that the medical humanities should play a vital role in such a project. However, we also maintain that this endeavour calls for a fundamental rethinking of the medical humanities. Such a rethinking should address the grounding assumptions about what the humanities are, as well as how they can interact with biomedicine in research, in the production and use of evidence, as well as in the practical art of care. Drawing on the work of Julia Kristeva (JK), ${ }^{3-6}$ we will argue that the medical humanities should fully acknowledge the pathological and healing powers of culture, and approach the human body as a complex biocultural fact. Accordingly, these cultural dimensions should no longer be construed as mere subjective aspects of medical care, but as being constituent of, and 'hard' factors behind, sickness and healing.

\section{CURA AND THE CHRONOTOPY OF CARE}

As is fitting, we begin our rethink of the ontology of the medical humanities by turning to a myth of origins. In Hatred and Forgiveness, ${ }^{6} \mathrm{JK}$ questions the dominant, biomedical concepts of 'health' and 'illness' by reading the Roman mythographer Hyginus' fable about the goddess Cura (Care) and the creation of man as a being belonging to different ontological domains and temporal orders. ${ }^{7}$ In the following, we will draw on and extend this reading. According to Hyginus' anthropogony, Cura crosses a river and on the other side bends down to the earth to pick up a clump of clay. From the clay she shapes the being that will become man. Jove comes along and Cura asks him to give life to the artefact. Jove complies and gives the gift of spirit to the shape formed by Cura, but a quarrel erupts over the name of the new creation. Should it be named after Cura or after the male celestial god? At this stage, Tellus, the God of Earth, intervenes and claims Cura's creation, arguing that he provided the material from which it was formed. Saturn, the God of time, settles the matter through an act of naming and by dividing and temporalising the possession of the various parts that comprise man: Jove is offered man's soul and Tellus his body, after man's death, while Cura will possess the creation in its lifetime since she made it. Saturn names the new being homo because it was originally shaped out of humus. Thus, human life as a composite assembly of spiritual (Jove) and material elements (Tellus) is held together by Cura's temporal care.

The mythology of Cura has been subject to various philosophical interpretations ${ }^{89}$ and has also 
been read in the context of the medical humanities. ${ }^{10} 11$ Characteristic of JK's reading, however, is her use of the myth to question the fundamental conceptual distinctions that underpin modern medicine and the medical humanities (as these are most often understood and practised). Moreover, this reading illuminates what we here will refer to as the chronotopic organisation of care. We use this Bakhtinian coinage to draw attention to the manner in which medical research and the practical art of care are assigned to different ontological domains (nature and culture) and to different time zones: The first to the universal stasis and Platonic non-time of biomedical evidence; the second to the mundane, biographical time of care as an intertextual co-creation of meaning in encounters between practitioners and patients. ${ }^{12}$

In JK's rendering, Jove's intervention and Saturn's introduction of the name of man separates homo as a creation (a state of being) from the continuous process of creativity (coming into being), represented by Cura, the initial forming agent and female artist behind the form of the human species. JK uses what she calls the 'circumscribed act' of the male gods as an allegory for the cultural distinction between health as a 'definitive state' and healing as a durative 'process with twists and turns in time'. ${ }^{6}$ Thus, the myth can be read as an allegory of how health is objectified into a condition of full being (a definitive state) outside time, while illness is conceived as the privation (steresis) of this original state of health and well-being. This binary schematic, moreover, separates biomedicine's concern with cure, that is, with nature, physis or bios as 'original' states of health or privation of health outside the human time of life, from the 'durative idea of care', and the liminal period between birth and death (zoe), the messy temporal space in which humans live and where sickness and healing actually occur simultaneously. In terms of the myth, we could say that biomedicine is only concerned with the product of Cura's art, not the performative act of creation and the messy work of translation between different gods and ontological domains that characterises all biological life in its singularity 'here and now'.

Due to the structure of temporal and ontological demarcations outlined above, biomedicine finds itself in constant need of 'repairment', and a bridging of the gap between bios and zoe through various supplements. As JK points out, remedies for the split between body and soul are often found in pharmaceuticals, or in the production of ideal images of 'good living' and model narratives about 'successful patients' ('the integrated disabled person', the 'empowered' or 'health literate patient' and so on). In research and theory, biomedicine attempts to 'bridge the gap' between bios and zoe by 'translating' knowledge about general conditions or states of health from the 'laboratory', a space constructed to be, ideally, outside the cultural time of the living and back into the singular biography and life context of the individual patient. ${ }^{13}$ Actually, a whole range of prominent practices such as 'knowledge translation' and 'health literacy' can be seen as 'soft' cultural supplements that aim at incorporating the individual patients and a 'subjective' perspective in medicine by turning 'cure' into 'care'. All these soft supplements rest on a distinction between the objective and subjective aspects of the healing process. In accordance with the logic of the supplement, however, they also have an implicit potential for undermining the oppositions. ${ }^{14}$

\section{MEDICINE AND HUMANITIES AS BIOCULTURAL PRACTICES}

The medical humanities then are conventionally conceptualised as an instrument of 'repairment', and reduced to a 'soft' supplement employed in 'extraordinary' situations of cross-cultural contact, or as means of persuasion when patients, for instance, do not understand the evidence or the proposed cure. We also see this clearly in the case of the Lancet Commission. When it aims to create awareness about the 'effect of cultural systems of values on health outcomes', ${ }^{1}$ it implicitly reinforces the ontological divide that in the first place caused the problem and the need for translation between epistemic and ontological domains.

Aspects of our approach fall within the so-called 'second wave' of the medical humanities (often referred to as 'critical medical humanities'). Fully in line with this critical agenda, we intend to go beyond the three Es that have been seen as characteristic of the first wave, ethics, education and experience, and emphasise a fourth E, namely entanglement. Medical humanities, as we and researchers of the second wave understand it, are 'deeply and irretrievably entangled in the vital, corporeal and physiological commitments of biomedicine'. ${ }^{15}$ In contrast to the 'second wave', however, we also insist that tackling this entanglement requires more than the mere application of perspectives from the humanities on medicine and healthcare with the aim of fostering more 'holistic understandings of the interaction between health, illness and disease'. ${ }^{16}$ The lesson we should learn from Cura is that the humanities, as much as the sciences, are a consequence of the bios-zoe divide. The humanities are themselves a product of epistemological and ontological divisions that underpin the current organisation of knowledge, and in this epistemic apparatus they are inscribed on the cultural side of the nature-culture divide. Hence, neither biomedicine nor the humanities can offer 'wholeness' (as 'romantic' and/or holistic notions of medical humanities often assume they can). Accordingly, we do not consider the humanities as a critical and potentially liberating perspective that can be applied to medicine as an object in need of repairment. Medical humanities should not be construed as a humanistic perspective on medicine. They should rather be seen as a cross-disciplinary and cross-cultural space for a bidirectional critical interrogation of both biomedicine (simplistic reductions of life to biology) and the humanities (simplistic reductions of suffering and health injustice to cultural relativism). On the one hand, this implies breaking with the culture-nature dichotomy and considering both the humanities and medicine as biocultural practices. On the other hand, it also implies understanding that boundary work requires boundaries, and that incommensurability between various partial disciplinary perspectives canand will-emerge. What we should maintain from the outset, however, is that biomedicine is not only culturally produced, but that the humanities are also materially productive; they create bodies and physical conditions. Like Cura in Hyginus' tale, cultures create different kinds of bodies and realities with medical implications: cultural discontent can produce pathologies, but increased understanding and analysis of the body as a complex biocultural fact can also be a potential source of healing.

\section{HEALING POWERS OF CULTURE: THE CASE OF SOUAD}

Over the last 3 years, JK and MRM have explored the pathological and healing powers of culture through their seminar on the 'Need to Believe' aimed at various professionals in the health sector who deal with cross-cultural discontent among adolescents. This seminar explores how health professionals should deal with the 'ideality disorder' of adolescents that follows from an absolute and unsatisfied need for an assimilative investment in an ideal otherness. Our secularised society offers no rites of initiation for these youngsters, and they are therefore exposed 
to 'a traumatic symbolic void' with potential pathological implications.

In Interpréter le mal radical, JK refers to the case of Souad, a teenage girl from a Muslim family who suffered from severe anorexia, 'a slow suicide addressed to her family and to the world' that subsequently metamorphosed into radicalisation: 'Souad walled herself up in silence and didn't get off the internet where, with her unknown accomplices, she exchanged furious emails against her family of 'apostates, worse than unbelievers', and prepared her voyage 'over there', in order to become the mistress of polygamous combatants, the mother of prolific martyrs or a kamikaze herself.' ${ }^{2}$

Souad was at first reticent about psychotherapy, but when confronted with the multicultural psychotherapeutic team, her attitude gradually changed. She started to find pleasure in narrating her life and in expressing her destructive urges and sufferings. Thus, she gradually began to reconnect with the French language. Together with other teenagers supported by the team, she started to attend writing and theatre workshops and to read Arabic poetry translated into French. Language, theatre and poetry now began to fill the 'symbolic void' and undid the nihilism. Roland Barthes wrote that if you find meaning in the plenitude of a language, 'the divine vacuum can no longer threaten'. ${ }^{17}$ In the case of Souad, her new cultural, symbolic and linguistic attachments represent a lot more than a soft cultural supplement to her biomedical treatment. Her reinvestment in 'the plenitude of a language' became a major creative and healing agency. Through the use and sharing of meaning and the pleasures of language, through conversation, theatre and poetry, Souad started to re-establish ties to the world and to her own body. Hence, a process of creativity and healing was initiated that encompassed both her body and soul.

\section{RETHINKING THE MEDICAL HUMANITIES}

To further develop and instantiate the reflections above, we are launching a global 'think tank' on medical humanities where we will invite medical researchers and professionals, humanists and social scientists to participate. The following fundamental issues will be discussed:

1. A new programme for the medical humanities should involve a radical concern with cultural dimensions of health as more than a subjective dimension outside the realm of medical science. We will explore the notions that all clinical encounters should be considered as cultural encounters in the sense that they involve translation between health as a biomedical phenomenon and healing as lived experience. Hence, our assumption is that the cultural crossings of care are not an exception but the norm. Given this, every clinical encounter should involve a simultaneous interrogation of the patient's and the doctor's co-construction of new and shared meanings that can create realities with medical consequences, not 'mere' symbols of 'real' medical issues. ${ }^{18}$ It was precisely such a co-construction of shared meanings that was achieved successfully in the case of Souad. This co-creation 'over here' addressed her anorexia and her desire to go 'over there'into the language of ISIL, and the land of biological death.

2. A new programme also implies a deconstruction of the difference between hard and soft science. As shown in the case of Souad, cultural, symbolic and linguistic attachments have medical implications. The humanities have creative and healing agency; they are not only instruments of care but of cure. This materially performative aspect of the humanities part of the medical humanities constellation needs closer attention and further theorisation.

3. The deconstruction suggested above also presupposes a radical questioning of the medical cultures behind the production and construal of evidence in medicine. As mentioned above, the dominant evidence-based approach in modern medicine runs the risk of exalting biology into an 'essential Being' and a normative stasis that turns the sick into persons who 'lack [... ] certain biological aptitudes'. Based on this understanding of disease as a lack of full being (steresis), sickness and difference are reduced to 'categories of difference': social and biological 'deviants' are seen as different in the same way. The biomedical discourse 'blends all disabled people together without taking into consideration the specificity of their sufferings and exclusions'. ${ }^{6}$ As an alternative to the epistemology of universal categories reducing difference to the same, the medical humanities should contribute to a 'singularised' approach to medicine. ${ }^{19}$ A singularised approach, however, is also different from merely considering the individual as a bearer of social/cultural meanings by including 'patients' preferences' in clinical decisions. The singularised approach and the possibility for symbolic reinvestment and sharing offered to Souad are not equal to a rational choice between treatment options. Nor is this the same as reducing the individual to biology by using the 'individual's genetic profile to guide decisions made in regard to the prevention, diagnosis, and treatment of disease. ${ }^{20}$ A singularised approach is contradictory to any reductionism, both culturally and biologically. It implies acknowledging that evidence itself is fundamentally singular; it is always evidence for a particular decision or a general category. Yet, universal categories are also essential in evidence-based decisions, and the notion of the singular, as Hegel underscored at the outset of the Phenomenology, is already itself a general notion. Knowledge about universal categories and generalised pathologies is thus needed both to identify the singular case as singular (ie, as distinct from a general category) and to create a linguistic, co-created place for transactions and translations between patients and medical specialists. Such general knowledge frames evidence-based decisions made locally, with reference to the particular patient, but should not be mistaken as evidence per se.

By tackling such fundamental issues, our 'think tank' aims to be the impetus for a radical revisioning of the role of the medical humanities in medical research and practice.

Twitter PPlease follow Eivind Engebretsen @eivinden and Julia Kristeva @JKristeva

Contributors JK provided the theoretical basis for the paper. EE and JØ conceptualized it and wrote the first draft. JK and MRM commented and revised the draft. JK provided the example. All authors have seen and approved the final manuscript.

Competing interests None declared.

Provenance and peer review Not commissioned; externally peer reviewed.

Open Access This is an Open Access article distributed in accordance with the Creative Commons Attribution Non Commercial (CC BY-NC 4.0) license, which permits others to distribute, remix, adapt, build upon this work non-commercially, and license their derivative works on different terms, provided the original work is properly cited and the use is non-commercial. See: http://creativecommons.org/ licenses/by-nc/4.0/

(c) Article author(s) (or their employer(s) unless otherwise stated in the text of the article) 2018. All rights reserved. No commercial use is permitted unless otherwise expressly granted. 


\section{REFERENCES}

1 Napier AD, Ancarno C, Butler B, et al. The Lancet commissions: Culture and health. The Lancet 2014;384:1607-39.

2 Kristeva J. Interpréter le mal radical. L'Infini 2016.

3 Kristeva J. A tragedy and a dream: disability revisited. Irish Theological Quarterly 2013;78:219-30.

4 Kristeva J. This incredible need to believe. New York: Columbia University Press, 2011

5 Kristeva J. Lettre au président de la république sur les citoyens en situation de handicap: à I'usage de ceux qui le sont et de ceux qui ne le sont pas. Paris: Fayard, 2003.

6 Kristeva J. Hatred and forgiveness. New York: Columbia University Press, 2012.

7 Hyginus, Fabulae 200-277. The myths of hyginus, publications in humanistic studies, no. 34. Lawrence: University of Kansas Press, 1960. http://www.theoi.com/Text/ HyginusFabulae 5 .html.

8 Reich W. Classic article: history of the notion of care. New York: Simon and Schuster, 1995:319-31.

9 Heidegger M, Macquarrie TJ, Robinson E. Being and time 1927. New York: Harper, 1962.

10 Kleinman A, Van Der Geest S. 'Care' in health care. Remaking the moral world of medicine. Medische Antropologie 2009;21:159-68.
11 Svenaeus F. Illness as unhomelike being-in-the-world: Heidegger and the phenomenology of medicine. Medicine, Health Care and Philosophy 2011;14:333-43.

12 Bakhtin M. Forms of time and of the chronotope in the novel, in the dialogical imagination: four essays. Austin: University of Texas Press, 1981.

13 Engebretsen E, Sandset TJ, Ødemark J. Expanding the knowledge translation metaphor. Health Res Policy Syst 2017;15:19.

14 Derrida J. Of grammatology. Baltimore: JHU Press, 2016.

15 Fitzgerald D, Callard F. Entangling the medical humanities. In: Whitehead A, Woods A, Atkinson S, MacNaughton J, Richards J, eds. The Edinburgh companion to the critical medical humanities. Edinburgh: Edinburgh University Press, 2016:35-6.

16 Hurwitz B, Dakin P. Welcome developments in UK medical humanities. J R Soc Med 2009;102:84-5.

17 Barthes R. Sades, fourier, loyola. Berkeley: University of California Press, 1989.

18 Sturm G, Baubet T, Moro MR. Culture, trauma, and subjectivity: the French ethnopsychoanalytic approach. Traumatology 2010;16:27-38.

19 Engebretsen $\mathrm{E}$. The medical concept of evidence and the irreducible singularity of being. Keynote speech at the Kristeva Circle in Stockholm 2016 http://www.kristeva. fr/eivind-engebretsen-the-medical-concept-of-evidence.html.

20 McMullan D. What is personalized medicine? Genome 2014:32-9. 